\title{
Characterization of Specific Essential Work of Fracture for various Fracture Modes on Thermoplastic Materials
}

\author{
Purnomo $^{1}$, PutuHadiSetyarini $^{2}$, DwiHadiSulistyarini $^{3}$, Ana HidayatiMukaromah $^{4}$, Bagas Faisal ${ }^{1}$ \\ ${ }^{1}$ Dept. of Mechanical Engineering, Faculty of Engineering, UniversitasMuhammadiyah Semarang, Semarang \\ 50272, Indonesia \\ ${ }^{2}$ Dept. of Mechanical Engineering, Faculty of Engineering, UniversitasBrawijaya, Malang 65145, Indonesia \\ ${ }^{3}$ Dept. of Industrial Technology, Faculty of Engineering, UniversitasBrawijaya, Malang 65145, Indonesia \\ ${ }^{4}$ Dept. of Health Analyst, Faculty of Health and Nursing, UniversitasMuhammadiyah Semarang, Semarang 50272, \\ Indonesia \\ *Corresponding author: purnomo@unimus.ac.id
}

\begin{abstract}
Purpose: This paper aims to provide an integrated overview of the current state for the characterization of fracture Mode I (opening), Mode II (in-plane shear), Mode III (out-of-plane shear), as well as Mixed-Mode based on the essential work of fracture (EWF) concept on neat thermoplastics as well as composite matrices. Methodology: This review paper synthesizes and expands a collection of literature using the same basic methods. Each document that has a same fracture mode is grouped, reviewed, and synthesized.The review generally covers important aspects of testing and related data reduction methods, and the results of EWF research in various different mode-type loading.Results: The character of fracture toughness in ductile material has been widely evaluated using the EWF approach. The use of this method has evolved not only for mode I fractures but also for mode II and mode III fractures. Applications: This can create an understanding of the topic of fracture characterization in various fracture modes based on the EWF concept for ductile material so that the readers can discuss the various findings presented in recent research papers.
\end{abstract}

Key words: Composite matrices, Essential work of fracture, Fracture characterization, Fracture mode

\section{INTRODUCTION}

Elastic fracture modeling cannot be used as a basis for analyzing fracture behavior in resilient materials especially polymeric materials. Various responses were carried out by researchers by conducting numerical simulations and experimental studies in investigating the behavior of elastic fractures by focusing on mixed-mode fractures.

In ductile material, the mode of loading experienced determines the mechanism of the fracture that occurs at the crack tip, whether the fracture is initiated due to tensile load or shear load. Furthermore, the fracture propagates with the dominant propagation mode, whether the tensile mode or the shear mode. In ductile steel, decreased shear mode fracture results in increased fracture toughness [1,2]. This phenomenon then realizes that to assess the toughness of mixed mode cracks in ductile crack material, it is also necessary to consider which model cracks dominate. This consideration must be made at the earliest. Therefore, determining the critical load is very necessary.

In order to determine the critical load, several criteria have been used including tensile strength transition criteria to determine the type of fracture, the critical loading criteria, and the bifurcation angle criteria [3,4]. Determination of the type of fracture is closely related to the type of loading, namely the imposition of tensile type or shear type. The second criterion, the critical loading criteria, is needed to analyze the occurrence of mixed-mode crack propagation. Bifurcation angle criteria are used to forecast the angle of cracks growth. This type of complex mode imposition is the dominant cause of fracture which is a sensitive problem in various structures. Based on the type of loading, there are three fracture modes namely I-mode, II-mode, and III-mode, shown in Figure 1 [5].

Other loading types are mixed mode which is a combination of fracture mode (modes I, II, and mixed-mode). Fracture mode I, also known as opening mode, is associated with normal tensile loads to the plane. The fracture mode II, which is often also called the shear mode, is related to the shear stress which is parallel to the fracture plane and at 90 degrees to the front fracture. The fracture mode III is also called the out-of-plane or tearing mode related to the shear stress which is parallel to the fracture plane also parallel to the front fracture. The direction of crack propagation is 90 degrees to the applied force field.

The character of the fracture becomes the main consideration in evaluating the fracture related to the selection of suitable material. Various testing techniques have been used by many researchers in relation to determining fracture toughness. Several types of loading modes, namely the loading mode I mode, mode II, mode III and mixed mode have been used. Mode I and mode II are evaluated using double cantilever beams and curved tip specimens, respectively. 

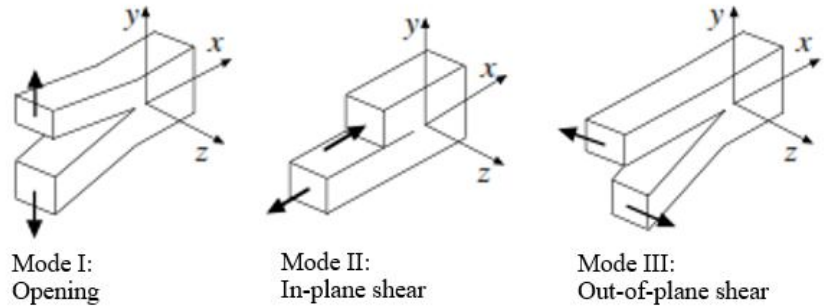

Figure 1: Schematic of Fracture Mechanics Modes

A popular approach to characterizing ductile material fractures is the EWF technique [6]-[7]. The basic concept of EWF is to divide the fracture energy of the test specimen into parts that are not related to geometry (essential work of fracture) and work related to geometry as a non-essential work [6]-[8]. This EWF approach is very popular with regard to the fracture characterization of thin polymers, especially in mode I fracture propagation in the plane stress state. Nevertheless, it is found that fracture propagation occurs in mode III and even mixed mode. The mixed modes that often occur are mode I-II and mode I-III.

The aim of this review is to provide a summary of fracture investigations in various loading modes evaluated by the EWF approach. Types of loading modes include loading mode I, mode II, mode III, and mixed-mode.

\section{FRACTURE UNDER MODE I-TYPE LOADING}

\subsection{Quasi-Static Loading Mode}

It has been widely reported that EWF is suitable for testing of polymeric material $[9,10]$. Specimens shape for quasi-static loading modes are single-edge notch tensile (DENT), shown in Figure 2, which are usually formed by one of several methods including injection molding[11-13], extrusion $[9,14]$, and hotpress[15,16]. In a quasi-static state, the test is carried out at a very slow speed so as to give the material a chance to deform totally[13,17]. Test data are grouped in EWF test data, namely essential work of fracture and non-essential work of fracture, as represented in Eq. 1.

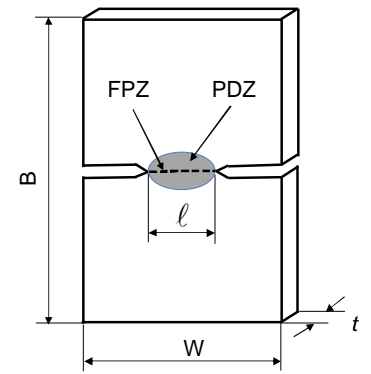

(a)

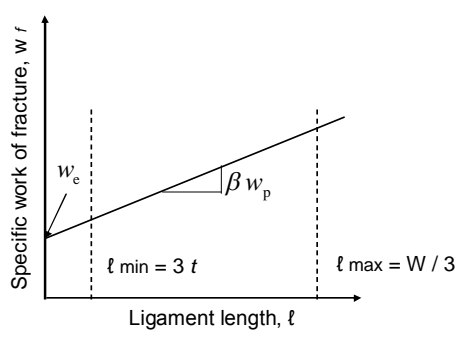

(b)
Figure2:Schematic of DENT specimen with FPZ (fracture process zone) and PDZ (plastic deformation zone) (a), and the data reduction (b).

$$
w_{f}=w_{\mathrm{e}}+\beta \cdot w_{\mathrm{p}} \cdot \ell(1)
$$

where $w_{e}$ is specific essential work of fracture, which is the energy used to create new fracture surfaces, and $\beta w p$ is specific non-essential work of fracture, which is the energy needed for plastic deformation work. The we parameter is the intercept values at $\ell=0$ and $\beta w_{p}$ is the slope of the line wf versus $\ell$.

The Annealing treatment can improve the essential fracture work (we) but reduce the plastic work of the material [13]. Some Research [18-20] has reported that fillers in the polymer matrix reduce the energy of materials fracture. In the EWF testing, many researchers varied the temperature $[9,17]$ and cross-head speed[21,22]. Based on their works, it can be concluded [6] that:

i) Work to create a new crack surface $\left(w_{e}\right)$ decreases with increasing temperature and increases by increasing cross-head speed or deformation rate. This tendency is not aligned for $\beta w p$ whose tendency is the opposite.

ii) The ductility increases with increasing testing temperature around glass temperature.

Their conclusions are confirmed by recent research[23,24]. The EWF testing on natural fiber reinforced polymer composites showed that we increased significantly with the amount of bamboo pulp fiber used in bamboo plastic composites but decreased with the increase of white mud in the bamboo plastic composites[25-27].

\subsection{Dynamic Loading Mode}

The EWF testing in dynamic loading (impact) mode using a single-edge notch bend (SENB) specimen proposed by Wu et al. [28] which is then followed by researchers up to now [7]-[29-31]. The EWF testing on natural fiber reinforced polymer composites showed that the impact fracture toughness $\left(w_{e}\right)$ was increased by increasing fiber content. Many researchers [18]-[25]-[32] concluded that the presence of fiber can increase the energy that is anticipated during the fracture process.

In terms of applying the EWF to impact loads, around the 1990 s, there was a debate about the suitability of this method for application. This is due to the fact that the test shows a negative slope of the $\mathrm{df}$ versus ligament length curve[33,34]. There are two common problems [6], namely (i) the fracture behavior shifts to brittle to increase crack growth, and (ii) the effect of plastic hinges so that the ligaments are not fully fractured.

To response to this debate, many researchers[35-37] introduced a new approach and a formula as shown in Eq. (2). 
Purnomo et al., International Journal of Emerging Trends in Engineering Research, 8(6), June 2020, 2381 - 2387

$$
\frac{U}{A}=\left(u_{o}+u_{d} \cdot \ell\right)(2)
$$

where U/A, $u_{o}$, and $u_{d}$ are specific fracture energy, limiting specific fracture, and the dissipative energy density, respectively. The formula as in Eq. (2) confirms the analogy that $u_{o}$ is equal to we and $u_{d}$ is equal to $w_{p}$. Until now, no published reports have been found regarding the determination of validity criteria and test conditions such as deformation rates and test temperatures. However, the phenomenon of oscillation at high deformation rates must be avoided [6].

\section{FRACTURE UNDER MODE II-TYPE LOADING}

In contrast to the EWF application in loading mode I, little research data can be found that examines the toughness of fracture mode II. This fracture test generally uses $\mathrm{V}$ notched and Iosipescu[38-40]. In mode II fracture (shear loading mode), determination of ligament length differs from fracture mode I. In the Iosipescu test, the maximum ligament length limit is not stated but the smallest ligament length is equal to the thickness of the specimen $(\ell=\mathrm{t})$ [41].

The EWF method has been widely developed to determine the toughness of mode II fractures. Kwon and Jar [42] were the pioneers in this case by testing Iosipescu on the $\mathrm{V}$ notch specimen. In their observations made at the same rate of deformation, they found that we depend on the thickness of the groove and its value is twice that of mode I fracture. The use of finite element analysis in high-density polyethylene shows that EWF mode II corresponds to the ligament length of $2 t<\ell o<W / 2$ [43]. This condition is also suitable for fractures from mode II which shift to mixed mode I-II. In layered material, Tan and Falzon[44] have tested the strength of mode II fractures on AS4 / PEKK composites. They reported that during the fracture process, the fiber experienced a malfunction to increase $w_{e}$ if subjected to normal stress and bending.

\section{FRACTURE UNDER MODE III-TYPE LOADING}

The EWF concept has been widely used to analyze the behavior of tearing fractures (mode III) especially fractures on ductile thin material. In this situation, a specific EWF is required for the occurrence of a mode III fracture in the form of a shear fracture. Meanwhile, non-EWF energy is used to carry out plastic deformation at the edge of the fractured part. Therefore, the specific work potential of fracture mode III can be mathematically written as in Eq. (3) [45] :

$$
w_{\text {IIIe }}=\frac{2 s \bar{\sigma}_{0} \gamma_{0}^{n+1}}{(n+1) 3^{(n+1) / 2}}+\left[\frac{\sigma_{0}}{2}\right]\left[\frac{\ell \gamma_{0}^{n}}{3^{(n+1) / 2}}\right]
$$

where $\gamma_{0}$ is the maximum shear strain. The ratio of the shear deformation work and shear fracture work is given by the ratio of the first term to the second term in Eq. (3), i.e. $4 /(n+1)(s / t)$. The lip width is probably proportional to the sheet thickness but is better measured experimentally from the fractured samples. In thin filmed polyester, a shift in loading mode behavior occurs, i.e. from loading type III mode to mode I[10,46-47].

Deformation and fracture mode III behavior can be analyzed using two approach models, the first is the two-zone model [48] and the second is the three-zone model [49]. The two-zone model approach was applied through testing trouser specimens. In this model, the tear fracture process is separated in two zones, namely the initial zone (Zone A) where the crack is initiated at height $\mathrm{h}$ which then propagates to reach the end of zone A which is also Zone B. The cracks propagate constantly in zone B (Figure 3). Based on Figure 1, the situation in zone $\mathrm{A}$ is elucidated by Bárány and co-workers[6,46] as follows:

1. The crack tip shape shift constantly as a result of stable loading.

2. There is a shift in the fracture mode to a fracture mode I that becomes dominant rather than a mode III fracture.

3. Cracks propagate accompanied by rising height of the plastic zone.
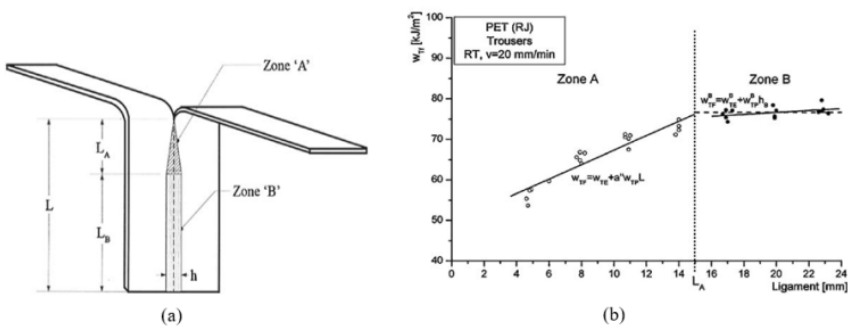

(b)

Figure 3:(a) Schematic diagram of trouser specimens, and (b) analysis of out-of-plane essential fracture work on polyethylene terephthalate [46].

In zone $\mathrm{A}$, the total fracture energy is expressed by mathematics formula as follow [46]:

$$
w_{T F}=w_{T E}+\alpha^{\prime \prime} w_{T P} \ell_{a}(4)
$$

where $\ell_{a}, \ell_{A}$, and $\alpha$ " is the torn ligament length, the ligament length at the end of zone, and a shape factor of the plastic zone, respectively.

In accordance with the EWF concept, the specific fracture work for tearing $\left(w_{T F}^{B}\right)$ in zone $\mathrm{B}$ at ligament length $\ell \mathrm{B}$ can be expressed mathematically as presented in Eq. (5)[48] :

$$
\frac{w_{T F}^{B}}{\ell_{B} t}=w_{T F}^{B}+w_{T P}^{B} h_{B}(5)
$$

The $w_{T F}^{B}$ parameter is the intercept of $w_{T F}^{B}-h_{B}$ at the plastic zone height $h_{B}=0$. 
In the three-zone model, zoning is composed of the initial, evolutionary, and established plastic zones that represent tear resistance (Figure 4). The outer plastic zone can be considered to consist of three different zones, namely zone I, V, and S. Zone I is also often referred to as the initial zone, which is created by increasing the initial load experienced before crack propagation occurs. The second zone is called zone $\mathrm{V}$ because it is shaped like the letter $\mathrm{V}$. Zone $\mathrm{S}$ is an area that has experienced plastic deformation that has been stable $(\mathrm{h}=$ constant).

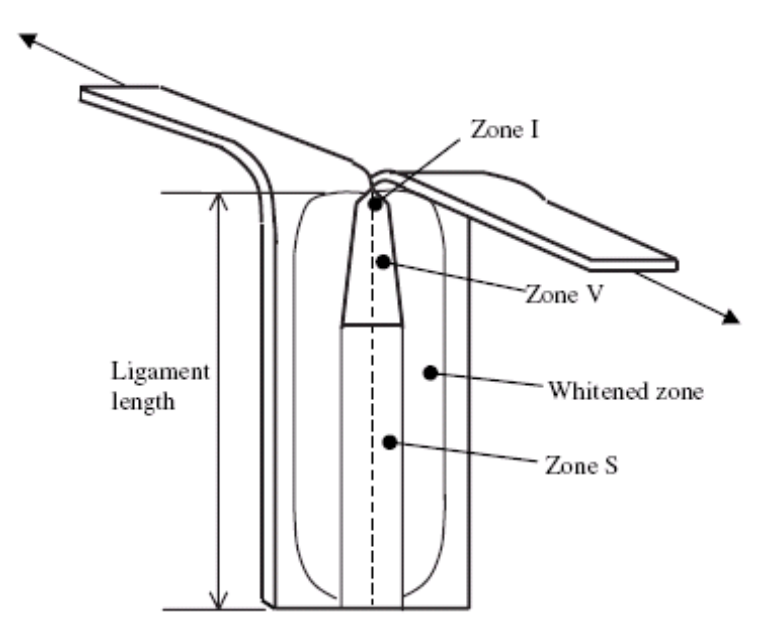

Figure 4:Three-Zone Model For Mode III Tearing Test [50]

Initial Zone (Zone I) is in the range $0<\mathrm{li}<\mathrm{Li}$. In this zone with ligament length li, the specific total work of fracture (wif) is presented in Eq. 6.

$$
w_{i f}=w_{i e} l_{i} t+w_{i p} A_{i} t
$$

where the parameters $w_{i}$ and $w_{i p}$ are specific essential and specific non-essential work of fracture, respectively. Subcript $i$ means zone I while $t$ is the thickness of the specimen. The Ai is the outer plastic deformation zone area (Figure 5) which is formulated:

$$
A_{i}=\frac{1}{2} h l_{i}=l_{i}^{2}
$$

Therefore, $w_{i f}$ can be written in another form as follows:

$$
w_{i f}=w_{i e}+w_{i p} l_{i}
$$

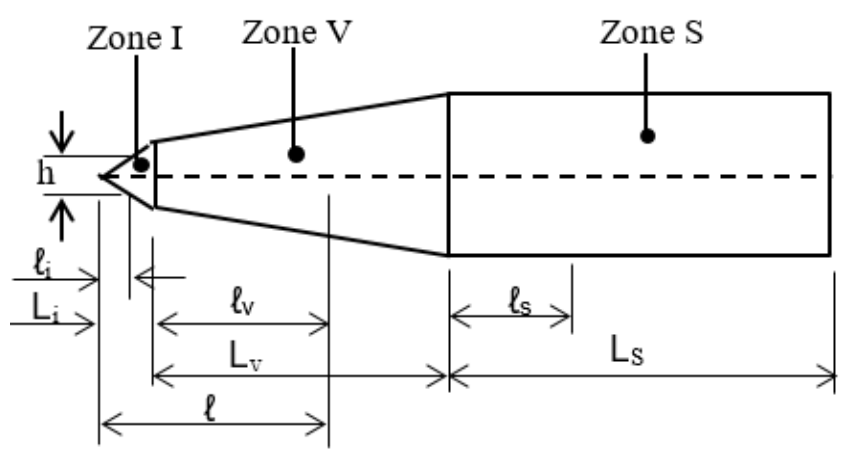

Figure 5:Plastic zones in three-zone models [50]
In zone $\mathrm{V}$ which is in the range $0<\mathrm{lv}<\mathrm{Lv}$, the total fracture work can be written as follows:

$$
W_{v f}=W_{v e}+W_{v p}=w_{v e}\left(L_{i}+l_{v}\right) t+w_{v p} A_{v} t
$$

The area of $A v$ can be written in mathematical form as follows:

$$
A_{v}=L_{i}^{2}+2 L_{i} l_{v}+\alpha l_{v}^{2}
$$

The $\alpha$ is the taper angle of zone $\mathrm{V}$ and is expressed as follows:

$$
\alpha=\frac{h_{s}-2 L_{i}}{2 L_{v}}
$$

The $L v$ parameter is determined by plotting specific total fracture work against ligament length. While $L i$ and $h s$ are determined directly from the specimens tested. Therefore, the specific total work of fracture can be written as in Eq. 12 as follows:

$$
w_{v f}=w_{v e}+\frac{w_{v p}\left(L_{i}^{2}+2 L_{i} l_{v}+\alpha l_{v}^{2}\right)}{L_{i}+l_{v}}
$$

\section{FRACTURE UNDER MIXED-MODE LOADING}

The problem of fracture mechanics is very complex. Therefore, this problem cannot be solved through one mode approach but with a mixed mode approach. The fracture phenomenon in this mixed mode state can occur by the presence of initial defects and the nature of the load concerning the structure. The simplest mixed mode fracture is the combination of mode I and mode II which occurs at the crack tip. Several standards have been introduced to analyze the behavior of mixed-mode I-II fractures which include maximum tangential strain [51,52], maximum tangential stress [53], minimum strain energy density [54], and maximum energy release rate [55]. In addition, experimental analysis has also been introduced by many researchers [56-58]. New formulas involving KI and KII have also been proposed by several researchers [59-61].

Essential mixed-mode fracture work of PC/ABS evaluated experimentally has been carried out by $\mathrm{Li}$ et al. [62]. They used DENT specimens with dimensions of $60 \mathrm{~mm} \times 30 \mathrm{~mm} \times$ $1.5 \mathrm{~mm}$ which ligament edges were given artificial cracks using a fresh razor blade (Figure 6). The loading angle $\varphi$ was varied from $900,750,450$, and 300 . They reported that the deviation in the direction of fracture propagation from the initial plane increased with a reduced load angle $\varphi$. This phenomenon is consistent despite the increased shear loading. It was also reported that reducing the load angle can increase the fracture energy. Fracture can be initiated from excessive loading oaf materials [63-65]. 


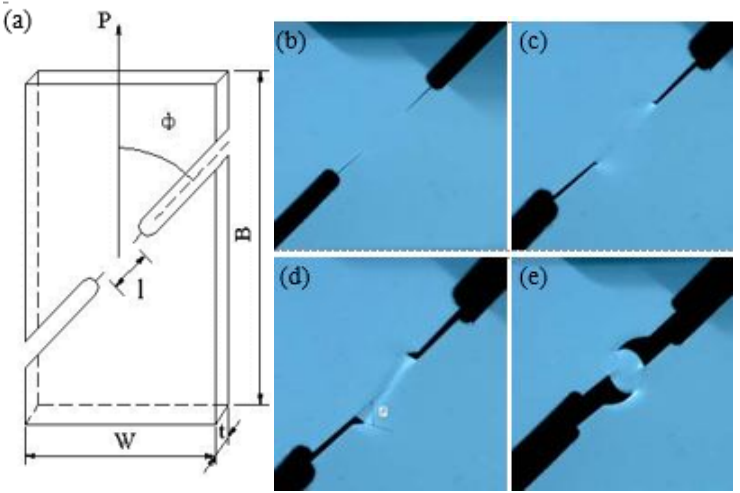

Figure 6: Schematic illustration of DENT for (a) mixed-mode test, (b) initial stage, (c) initial propagation, (d) developing propagation, and (e) breaking phase. The parameters $\mathrm{P}$ and $\mathrm{l}$ are load and ligament length, respectively [62].

\section{CONCLUSION}

Many works have been done to investigate mechanical fractures using the EWF approach. This method has been widely developed to evaluate mechanical fractures in various modes including mixed modes. Tests in each fracture mode using specimens with different shapes. In fact, many researchers have reported that the common mix mode consists of mixed modes I-II and I-III. Two approach models namely the three-zone model and the two-zone model are very suitable for investigating tearing fractures (mode III). However, the three-zone model has higher accuracy than the two-zone model. So that the results of the analysis of fracture toughness in each mode fracture are valid, the prediction of fracture toughness based on the mode type-loading should be compared with the results of experimental tests. The EWF method is well established so that in the use of testing methodologies and specimen selection it should be standardized.

\section{ACKNOWLEDGEMENT}

The authors acknowledge the support from Directorate of Research and Community Service, The Ministry of Research, Technology and Higher Education of the Republic of Indonesia..

\section{REFERENCES}

1. A. Hohenwarter, andR. Pippan.Fracture and fracture toughness of nanopolycrystalline metals produced by severe plastic deformation, Philos Trans A Math Phys Eng Sci. 373(2038), 20140366, 2015. doi: 10.1098/rsta.2014.0366

2. A. Pineau, A.A. Benzerga, andT. Pardoen. Failure of metals I: Brittle and ductile fracture, ActaMaterialia, 107, 424-483, 2016.

doi:10.1016/j.actamat.2015.12.034

3. A.R. Torabi,andB. Saboori. Experimental and theoretical investigation of mixed mode I/III brittle fracture of U-notched polystyrene components, The
Journal of Strain Analysis for Engineering Design, 53(1),15-25, 2018.

4. A.R. Torabi, and S.M. Abedinasab.Fracture study on key-hole notches under tension: two brittle fracture criteria and notch fracture toughness measurement by the disk test, Experimental Mechanics, 55(2): 393-401. doi:10.1007/s11340-014-9949-0

5. C. Barile, C. Casavola, B. Gambino, A. Mellone, and M. Spagnolo. Mode-I Fracture Behavior of CFRPs: Numerical Model of the Experimental Results, Materials (Basel), 12(3), 513, 2019.doi: 10.3390/ma12030513

6. T. Bárány, T. Czigány, and J. Karger-Kocsis. Application of the essential work of fracture (EWF) concept for polymers, related blends and composites: A review, Progress in Polymer Science, 35, 1257-1287, 2010.

doi:https://doi.org/10.1016/j.progpolymsci.2010.07.001

7. M. Subri, and P. Setyarini.Fracture development and deformation behavior of zeolite-filled high densitypolyethylene annealed composites in the plane stress fracture,FME Transactions, 46(2), 165-170, 2018. doi:10.5937/fmet1802165S

8. A.L. Pascual, C.S. Beeman, E.P. Hicks, H.M. Bush, and R.J. Mitchell. The essential work of fracture of thermoplastic orthodontic retainer materials, The Angle Orthodontist, 80, 554-561, 2010. doi:10.2319/042809-232.1

9. F.M. Peres, J.R. Tarpani, C.G. Schön. Essential Work of Fracture testing method applied to medium density polyethylene, Procedia Materials Science, 3, 756-763, 2014. doi:10.1016/j.mspro.2014.06.124

10. M.S. Islam, E. Andreasson, S. Kao-Walter. Trouser tear testing of thin anisotropic polymer films and laminates, International Journal of Fracture,1, 1-15, 2019. doi: 10.1007/s10704-019-00389-3

11. Purnomo, R. Soenoko, Y.S. Irawan, and A, Suprapto. Deformation under quasi static loading in high density polyethylene filled with natural zeolite, Journal of Engineering Science and Technology, 12, 1191-1203, 2017.

12. M. Kroon, E. Andreasson, V. Petersson, and P.A. Experimental and numerical assessment of the work of fracture in injection-moulded low-density polyethylene, Engineering Fracture Mechanics, 192, 1-11, 2018. doi: 10.1016/j.engfracmech.2018.02.004

13. Purnomo,and P.H. Setyarini. Atmospheric-pressure annealing effect on the impact fracture toughness of injection-molded zeolite-HDPE composite, International Review of Mechanical Engineering, 12(6),556-562, 2018. https://doi.org/10.15866/ireme.v12i6.15034

14. I.I. Cuesta, E. Martinez-Pañeda, A. Díaz, and J.M. Alegre. The Essential Work of Fracture parameters for 3D printed polymer sheets, Materials \& Design, 181, 107968, 2019.

doi:https://doi.org/10.1016/j.matdes.2019.107968

15. J. Gámez-Pérez, J.C. Velazquez-Infante, E. Franco-Urquiza, P. Pages, O.O. Santana, M.L. Maspoch, and F. Carrasco. Fracture behavior of quenched 
Purnomo et al., International Journal of Emerging Trends in Engineering Research, 8(6), June 2020, 2381 - 2387

poly(lactic acid), EXPRESS Polymer Letters, 5(12), 82-91, 2017. doi:10.3144/expresspolymlett.2011.9

16. X. Liu, B. Yang, L. Lu, Z. Wan, Y. Tang. A Thermoplastic Multilayered Carbon-Fabric/Polycarbonate Laminate Prepared by a Two-Step Hot-Press Technique, Polymers, 10(7), $720,2018$. doi: 10.3390/polym 10070720

17. I. Giannakopoulos, and A.C.Taylor.An essential work of fracture study of the toughness of thermoset polyester coatings, Progress in Organic Coatings, 78, 265-274, 2015.

doi:https://doi.org/10.1016/j.porgcoat.2014.08.009

18. I. Giannakopoulos, and A.C. Taylor, A. C. An essential work of fracture study of the toughness of thermoset polyester coatings, Progress in Organic Coatings, 78, 265-274, 2015.

19. D. Pedrazzoli, F. Tuba, V.M. Khumalo, A. Pegoretti, and J. Karger-Kocsis. Mechanical and rheological response of polypropylene/boehmite nanocomposites, Journal of Reinforced Plastics and Composites, 33(3), 252-265, 2014. doi:10.1177/0731684413505787

20. B. Hulugappa, M.V. Achutha, and B. Suresha. Effect of Fillers on Mechanical Properties and Fracture Toughness of Glass Fabric Reinforced Epoxy Composites, Journal of Minerals and Materials Characterization and Engineering, 4(1), 1-14, 2016. doi:10.4236/jmmce.2016.41001

21. C.G. Skamniotis, Y. Patel, M.N. Charalambides, andM. Elliott. Fracture investigation in starch-based foods, Interface Focus, 6(3): 20160005, 2016.

22. H. Pan, S. Devasahayam, and S. Bandyopadhyay. Study of microstructure and fracture properties of blunt notched and sharp cracked high density polyethylene specimens, Scientific Reports, 7(1), 1-13, 2017. doi:10.1038/s41598-017-03884-6

23. C.J.V.D. Oliveira, R.P. Weber, S.N. Monteiro, H.C. Vital, and M.L. Dias. Evaluation of Fracture Toughness of Ultraviolet-Irradiated Polycarbonate Using the Essential Work of Fracture Method, Materials Research, 21(1),e20171079, July 2018. doi:http://doi.org/10.1590/1980-5373-mr-2017-1079

24. P. Zhang, L. Ma, F. Fan, Z. Zeng, C. Peng, P.E. Loya, Z. Liu, Y. Gong, J. Zhang, X. Zhang, P.M. Ajayan, T. Zhu, J. Lou. Nature Communications, Vol.5, Article number: 3782, 2014.

25. Y. Xian, D. Ma, C. Wang, G. Wang, L. Smith, and H. Cheng. Characterization and Research on Mechanical Properties of Bamboo Plastic Composites, Polymers (Basel), 10(8), 814, August 2018.

26. K.N. Keya, N.A. Kona, F.A. Koly, K.M. Maraz, M.N. Islam, and R.A. Khan. Natural fiber reinforced polymer composites: history, types, advantages and applications, Materials Engineering Research, 1(2), 69-85, 2019.

doi:https://doi.org/10.25082/MER.2019.02.006

27. L. Mohammed, M.N. Ansari, G. Pua, M. Jawaid, andM.S. Islam. A Review on Natural Fiber Reinforced Polymer Composite and Its Applications,
International Journal of Polymer Science,2015.ID 243947.

doi: $10.1155 / 2015 / 243947$

28. J.S. Wu, Y.W. Mai, and B. Cotterell. Fracture-toughness and fracture mechanisms of PBT/PC/IM blend. 2. Fracture properties,Journal ofMaterials Science, 28(12), 3373-3384, 1993.

29. R. Soenoko, A. Suprapto, Y.S. Irawan. Impact fracture toughness evaluation by essential work of fracture method in high density polyethylene filled with zeolite, FME Transactions, 44(2), 180-186, 2016. doi:10.5937/fmet1602180P

30. G. Gao, Z. Li, M. Negahban. Dynamic fracture analysis of polycarbonate by the optical of caustics, Procedia Materials Science, 3, 165-176, 2014. doi:https://doi.org/10.1016/j.mspro.2014.06.031

31. H. Ge, G. Singh, and S.C. Mantell. Fracture behavior of degraded polyethylene thin films for solar thermal applications, Energy Procedia, 30, 783 - 792, 2012. https://doi.org/10.1016/j.egypro.2012.11.089

32. A. May-Pat, A. Valadez-González, P.J. Herrera-Franco. Effect of fiber surface treatments on the essential work offracture of HDPE-continuous henequen fiber-reinforced composites, Polymer Testing, 32(6), 1114-1122, 2013.

doi:https://doi.org/10.1016/j.polymertesting.2013.06.006

33. T. Vu-Khanh. The impact fracture of polymers: unanswered questions, Trends in Polymer Science, 5, 356-360, 1997.

34. C.R. Bernal,andP.M. Frontini. Determination of fracture-toughness in rubber-modified glassy-polymers under impact conditions, Polymer Engineering \& Science, 35(21), 1705-1712, 1995. doi:https://doi.org/10.1002/pen.760352107

35. O. Okada, H. Keskkula, D.R. Paul. Fracture toughness of Nylon 6 blends with maleated ethylene/propylene rubbers, Polymer, 41(22), 8061-8074, 2000. doi:https://doi.org/10.1016/S0032-3861(00)00163-4

36. R.A. Kudva, H. Keskkula, andD.R. Paul. Fracture behavior of nylon 6/ABS blends compatibilized with an imidized acrylic polymer, Polymer, 41, 335-349, 2000.

doi: https://doi.org/10.1016/S0032-3861(99)00244-X

37. G. Ozkoc, G. Bayram, and E. Bayramli. Impact essential work of fracture toughness of ABS/polyamide-6 blends compatibilized with olefin based copolymers, Journal of Materials Science, 43, 2642-2652, 2008. doi:10.1007/s10853-008-2483-7

38. K.B. Dahl,and K.A. Malo. Linear shear properties of spruce softwood, Wood Sci Technol, 43(5-6), 499-525, 2009. doi:10.1007/s00226-009-0246-5

39. S. Islam, S. Kao-Walter, G. Yang. Measuring shear fracture toughness with a modified shear test specimen; in: Anaheim, CA, USA, 2015.

40. A. Krishnan, andL.R. Xu. A short-beam shear fracture approach to measure the mode II fracture toughness of materials with preferred interfaces, International Journal of Fracture, 169(1), 15-25, 2011. doi:10.1007/s10704-010-9579-1 
Purnomo et al., International Journal of Emerging Trends in Engineering Research, 8(6), June 2020, 2381 - 2387

41. H.J. Kwon, and P.Y. Jar. Toughness of high-density polyethylene in shear fracture, International Journal of Fracture, 145(2), 123-133, 2007. doi:10.1007/s10704-007-9110-5

42. H.J. Kwon, and P.Y.B Jar. Fracture toughness of polymers in shear mode, Polymer, 46(26), 12480-12492, 2005. doi:https://doi.org/10.1016/j.polymer.2005.10.074

43. M.S. Islam, S. Kao-Walter, G. Yang. Study of ligament length effect on mode mix of a modified in-plane shear test specimen, Materials Performance and Characterization, 5(3), 249-259, 2016. doi:https://doi.org/10.1520/MPC20150058

44. W. Tan,and B.G. Falzon. Modelling the nonlinear behaviour and fracture process of AS4/PEKK thermoplastic composite under shear loading, Composites Science and Technology, 126, 60-77, 2016. doi:10.1016/j.compscitech.2016.02.008

45. Y.W. Mai. On the plane stress essential fracture work in plastic failure of ductile materials, International Journal of Mechanical Sciences, 35(12), 995-1005, 1993. doi:https://doi.org/10.1016/0020-7403(93)90051-U

46. T. Bárány, F. Ronkay, J. Karger-Kocsis, and T. Czigány. In-plane and Out-of-plane Fracture Toughness of Physically Aged Polyesters as Assessed by the Essential Work of Fracture (EWF) Method, International Journal of Fracture, 135(1-4), 251-265, 2005. doi:10.1007/s10704-005-3947-2

47. A. B. Martínez, A. Segovia, J. Gamez-Perez, and M.L. Maspoch. Essential work of fracture analysis of the tearing of a ductile polymer film, Engineering Fracture Mechanics, 77(14), 2654-2661, 2010. doi:10.1016/j.engfracmech.2010.07.017

48. J.S. Wong, D. Ferrer-Balas, R.K. Li, Y.W. Mai, M.L. Maspoch, H.J. Sue. On tearing of ductile polymer films using the essential work of fracture (EWF) method,Acta Mater, 51(16), 4929-4938, 2003. https://doi.org/10.1016/S1359-6454(03)00335-5

49. H. Min (2008). Study of two models for tearing resistance assessment using essential work of fracture method, M.S. thesis, Dept. Mechanical Eng., Blekinge Institute of Technology, Sweden, 2008

50. H.S. Kim, and J. Karger-Kocsis. Tearing resistance of some co-polyester sheets,ActaMaterialia, 52(10), 3123-3133, 2004. doi: https://doi.org/10.1016/j.actamat.2004.03.013

51. M.M. Mirsayar. Mixed mode fracture analysis using extended maximum tangential strain criterion, Materials \& design, 86, 941-947, 2015. doi:https://doi.org/10.1016/j.matdes.2015.07.135

52. M.R. Ayatollahi, and B. Saboori, B. Maximum tangential strain energy density criterion for general mixed mode I/II/III brittle fracture, International Journal of Damage Mechanics, 24(2), 263-278, 2015. doi:https://doi.org/10.1177/1056789514530745

53. M.M. Mirsayar, and P. Park. Modified maximum tangential stress criterion for fracture behavior of zirconia/veneer interfaces, $J$ MechBehav Biomed Mater, 59, 236-240, 2016.

doi:10.1016/j.jmbbm.2015.11.037
54. N. Benamara, A. Boulenouar, and M. Aminallah. Strain energy density prediction of mixed-mode crack propagation in functionally graded materials, PeriodicaPolytechnica Mechanical Engineering, 61(1), 60-67, 2017. doi:10.3311/PPme.9682

55. C. Hou, X. Jin, X. Fan, R. Xu, and Z. Wang. A generalized maximum energy release rate criterion for mixed mode fracture analysis of brittle and quasi-brittle materials, Theoretical and Applied Fracture Mechanics, 100, 78-85, 2019. doi:https://doi.org/10.1016/j.tafmec.2018.12.015

56. J. Akbardoost, and M.R. Ayatollahi.Experimental analysis of mixed mode crack propagation in brittle rocks: The effect of non-singular terms, Engineering Fracture Mechanics, 129: 77-89, 2014. doi:https://doi.org/10.1016/j.engfracmech.2014.05.016

57. F. Alizadeh, and N. Choupani.Mixed-mode fracture toughness characterization of dentistry cements based on numerical and experimental analysis, The Journal of Adhesion, 91(6), 488-503, 2015. doi:10.1080/00218464.2014.924411

58. M.R. Ayatollahi, M.R.M. Aliha, and M.M. Hassani. Mixed mode brittle fracture in PMMA-An experimental study using SCB specimens, Materials Science and Engineering A, 417(2), 348-356, 2006.

59. S. Devalapur, Basawaraj, and H.V. Lakshminarayana. Studies on mixed mode fracture: prediction and verification, International Journal of Mechanical and Industrial Technology, 2, 130-137, 2014.

60. W. Hua, J. Li, S. Dong, and X. Pan. Experimental study on mixed mode fracture behavior of sandstone under water-rock interactions, Processes 2019, 7(2), 70. https://doi.org/10.3390/pr7020070

61. K. Sedighiani, J. Mosayebnejad, H. Ehsasi, andH.R. Sahraei.The effect of $\mathbf{T}$-stress on the brittle fracture under mixed mode loading, Procedia Engineering,10,774-779, 2011. https://doi.org/10.1016/j.proeng.2011.04.128

62. H. Li,, G. Jiang, Q. Fang, and T. Wang. Experimental investigations on the mixed-mode essential fracture work of PC/ABS alloy, Journal of Mechanical Science and Technology, 29(1), 33-38. 2015. doi:10.1007/s12206-014-1205-0

63. M. Bhandari, Mechanical Computations of Functionally Graded Material Plate Subjected to Transverse Load, International Journal of Emerging Trends in Engineering Research, 8(4), 969 - 974, 2020. https://doi.org/10.30534/ijeter/2020/13842020

64. V.A. Ivanov, Wear Resistance of Repair Composite Materials with Ceramic Fillers, International Journal of Emerging Trends in Engineering Research, 8(4), 1192 - 1195, 2020. https://doi.org/10.30534/ijeter/2020/39842020

65. A.E. Ismail and A.F. Mat Beyi, A Brief of Sources of injury and failure during stent implantation, International Journal of Emerging Trends in Engineering Research, 8(3), 667- 673, 2020. https://doi.org/10.30534/ijeter/2020/10832020 